Research Article

Eva Brumercikova* and Bibiana Bukova

\title{
Proposals for Using the NFC Technology in Regional Passenger Transport in the Slovak Republic
}

https://doi.org/10.1515/eng-2020-0005

Received Nov 05, 2019; accepted Jan 29, 2020

\begin{abstract}
NFC (Near Field Communication) devices are used in contactless payment systems, similar to those used in credit cards and electronic ticket smart cards, and they allow a mobile payment to replace or supplement these systems. The trend of increasing the quality of transport services also includes the use of progressive information technologies. The article focuses on the use of NFC technology in regional passenger transport. In the first proposal, the implementation of NFC technology in the form of an electronic wallet in a regional contactless chip card is being considered. In the second proposal we deal with the implementation of NFC technology in regional passenger transport using mobile phones with an active NFC chip. The proposals use Check-In/Check-Out validation, where validators are placed in vehicles. In both proposals it would be possible to create a link to EMV (Europay/MasterCard/VISA) technology, and thus to provide a linking of a contactless smart card, possibly a mobile phone to the passenger's personal account.
\end{abstract}

Keywords: determinant, distribution logistics, construction industry

\section{Introduction}

As part of a VEGA project there was realised an empirical research in 2018 whose aim was to find out an innovative method of passenger handling which would be interested

\footnotetext{
^Corresponding Author: Eva Brumercikova: University of Zilina, The Faculty of Operation and Economics of Transport and Communications, Department of Railway Transport, Univerzitna 1, 01026 Zilina, Slovakia; Email: eva.brumercikova@fpedas.uniza.sk Bibiana Bukova: University of Zilina, The Faculty of Operation and Economics of Transport and Communications, Department of Railway Transport, Univerzitna 1, 01026 Zilina, Slovakia; Email: bibiana.bukova@fpedas.uniza.sk
}

for citizens of the Slovak Republic. Based on the research respondents would prefer NFC technology for their handling in public passenger transport. There are the following requirements of the passenger handling technology: simplicity, safety, compatibility, and speed of handling [13].

NFC technology is based on a wireless communication between various devices (similarly to Wi-Fi and Bluetooth). NFC enables a data transfer with a high speed for short distances through a simple bringing two devices closer. These devices may be two mobile phones, a phone and a reader, or a mobile phone and an NFC chip. NFC technology is an extension of RFID technology (Radio Frequency Identification), and NFC is compatible with its passive variant. After several years of RFID technology development NFC technology was approved as an ISO/IEC standard in 2003. In 2004 the companies Nokia, Sony, and Philips founded a non-profit organisation NFC Forum which focuses on the support for safety, simplicity of usage and popularisation of NFC technology. The aim of the organisation is to educate businesses about the technology, to promote norms and to propose standards of NFC technology in order to ensure compatibility; this guarantees that any NFC technology-supported device may be used with another NFC device, or an NFC chip [4-6].

NFC technology requires an NFC chip. Each contactless card, a sticker with a passive NFC chip (in case of a passive connection) or with an active NFC chip (in case of a mobile phone) may be used as a medium. For the handling system to become a payment one it is necessary to determine the way how the payment for buying a ticket will be realised. One of the options is to utilise a clearing centre to account the proceeds for carriers. Another option is to link the entire process to bank institutions using their payment systems, i.e. to introduce NFC technology using EMV technology. In such a case the funds would be credited to a carrier $[7,8]$.

๑ Open Access. ๑ 2020 E. Brumercikova and B. Bukova, published by De Gruyte Attribution 4.0 License 


\section{A Proposal of the Implementation of NFC Technology in Regional Passenger Transport using an Electronic Wallet on a Contactless Chip Card}

The first proposal for the implementation of NFC technology into regional passenger transport would be the option to introduce an entire complex system with a suggested name "regional passenger transport card" based on a contactless chip chard which would work in a "Card Emulation" communication mode. Prior to the implementation the entire proposal is required to be applied to a rail as well as road network. This proposal should originate from the decision of the Government of the Slovak Republic, Ministry of Transport and Construction in cooperation with the Transport Authority regarding creating the system of a "regional passenger transport card". The goal of the proposal would be making the regional passenger transport more attractive; it would be incorporated into the Development Strategy of Public Passenger Transport of the Slovak Republic by 2020 and the document Public Passenger Transport 2030.

On the basis of the analysis and information coming from applications abroad [9-15] it would be recommended to use Check-In/Check-Out validation for the product of a "regional passenger transport card". With regard to the category of trains the validators would have to be placed into vehicles or onto boarding points, so it would be possible to determine the category of train the passenger would be carried in. In case of bus transport these Check-In (entrance) validators may be placed into vehicles in the same way as they are placed there currently, supplemented with so called Check-Out (exit) validators.

Railway stations and bus stations would have to be equipped with stationary automats to charge a credit onto a card. Equally it would be possible to buy a ticket using a card in a cash desk in that way so the entire system could be operated even by a conservative group of inhabitants, or in that way so passengers could gradually get used to the system of handling (some stations of Železničná spoločnost' Slovensko already do possess ticket windows with an NFC chip) [16-18].

Since the system of passenger handling would be based on a contactless chip card (electronic wallet), the passenger would have to obtain a contactless chip card to implement the technology; the card could be:
- standard - it would be intended for occasional passengers who do not utilise public passenger transport regularly. Such a card would be available for a low charge - production costs - and would have a longer expiration period. The card could be transferable (i.e. without a photograph of the card holder) considering the irregularity of transport of one passenger;

- personal - it would be intended for pupils, students and work force who do utilise public passenger transport regularly. In order to issue such a national card it would be required to provide personal data (e.g. in order to grant a discount) and a photograph of the card holder $[19,20]$.

The usage of a contactless chip card within the complex system of a "regional passenger transport card" could be conditioned in two ways:

1. for carriers who would not be registered in the system the contactless chip card could be used as a medium of a bought ticket (Figure 1). Under this proposal a system of electronic tickets - e-ticketing, i.e. buying a ticket using a contactless chip card would be applied [12, 21].

2. a flowchart of using the contactless chip card in case of transport by carriers, who would be registered in the complex system of a regional public passenger transport card, is depicted in Figure 2. The role of a passenger would be to monitor if there is a sufficient credit on their contactless chip card. This duty, however, could be removed using EMV technology [22, 23], which means that a payment card of a passenger would fulfil a function of a contactless chip card, i.e. a medium, at the same time. Since not all passengers are owners of payment cards, a combination of a separate contactless chip card for children and for passengers without a payment card would be possible; and the second group would consist of passengers with a payment card. Since a passenger could be identified using the contactless chip card or the payment card, the fare would be calculated as a standard or a reduced one. Both, a contactless chip chard and a payment card may have defined loyalty discounts of carriers since NFC technology enables it.

In order to redistribute the proceeds a clearing centre should be established. Its role would be to send the proceeds to carriers or in case of applying EMV technology to send information about the carrier, who would subsequently be sent money to by the passenger's bank. 


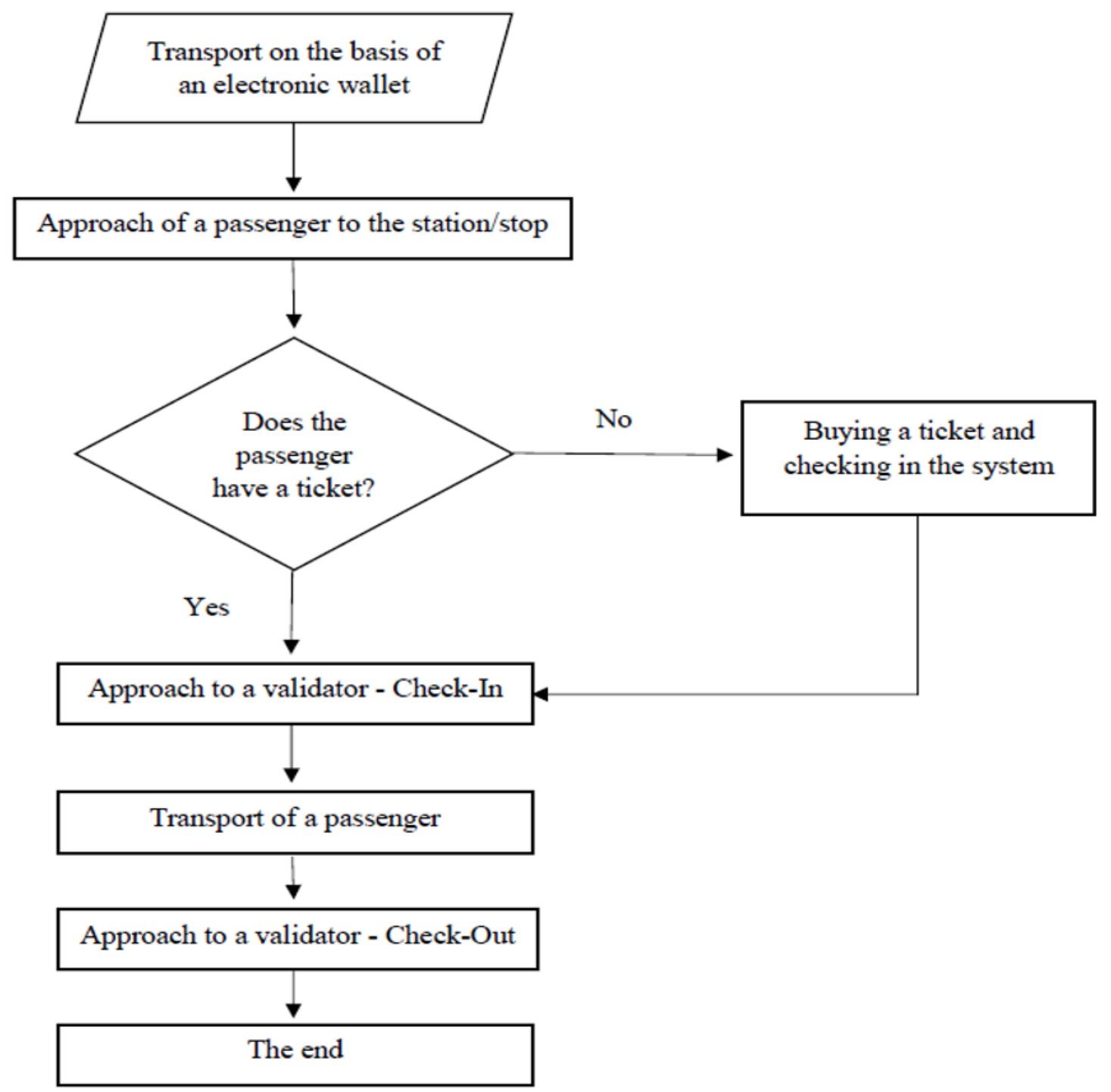

Figure 1: Transport using a Regional Passenger Transport Card in Case of Unregistered Carriers (Source: the Authors).

\section{The Implementation of NFC Technology in Regional Passenger Transport Using Mobile Phones with an Active NFC Chip}

Another option in case of applying NFC technology in regional passenger transport is the usage of mobile phones with an active NFC technology (a chip). Association of lecturers and career counsellors, which has been registered at Ministry of Interior of the Slovak Republic since 2012, divided the society into 8 generations. Currently the so called
Y generation (years of birth 1977 - 1994) is economically active; it is influenced with the development of social media. Potential customers (passengers) may also include the so called Z generation (years of birth 1995 - 2010) and the so called alfa generation (born after 2011). According to the Association of lecturers and career counsellors it is the alfa generation who can intuitively control smartphones and tablets since their toddler age. Nowadays even children attending kindergartens do have mobile phones and for children attending schools a smartphone represents a common part of life [24]. This knowledge implies that the usage of mobile phones with an active NFC chip has a big potential of application also within handling the passengers who travel by public passenger transport. 


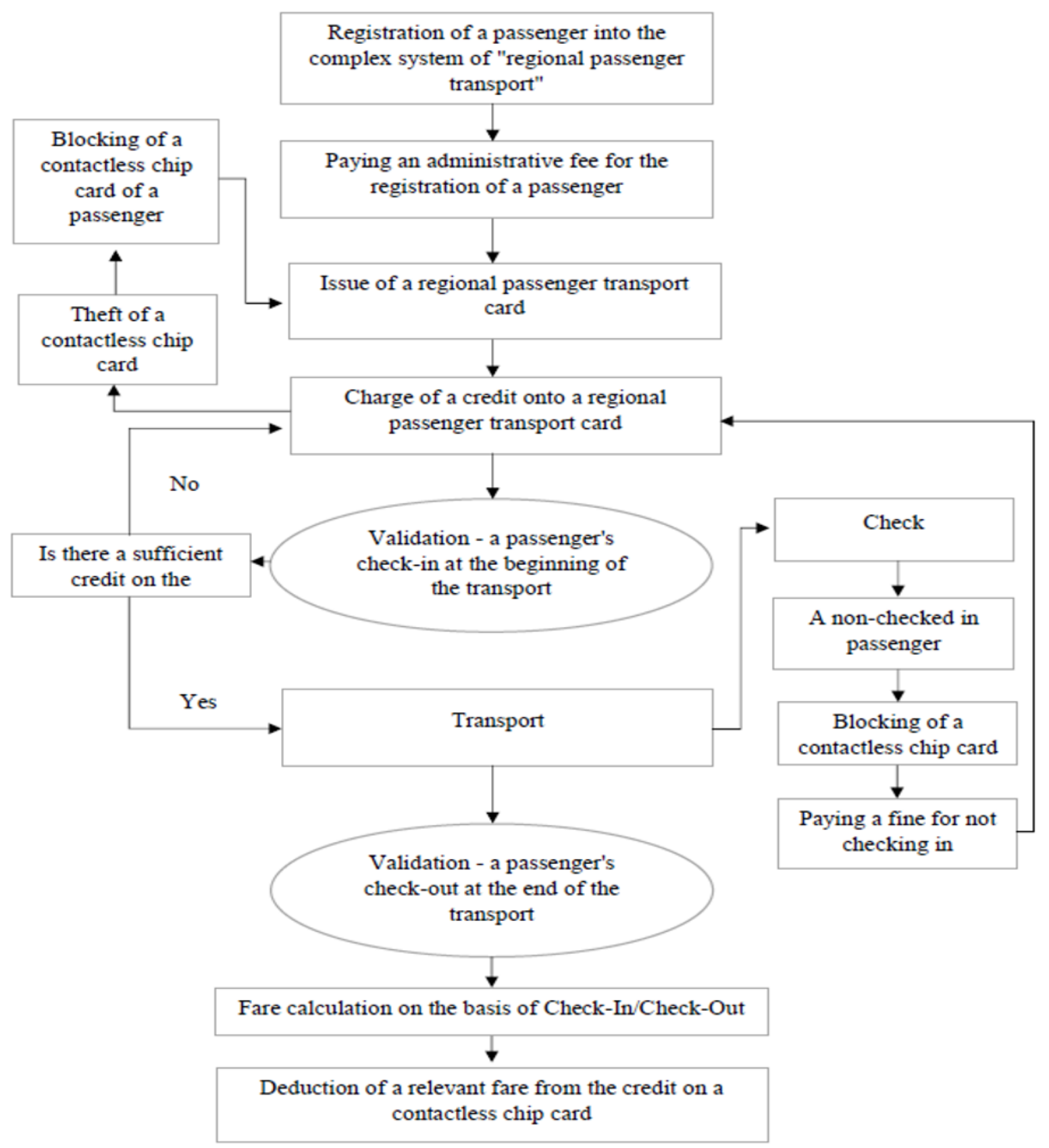

Figure 2: A Model Diagram of Using NFC Technology with a Contactless Chip Card at Registered Carriers (Source: the Author).

A mobile phone with an active NFC chip can be linked to banks (using EMV technology) where it would be possible to pay for a ticket directly from a personal account of a passenger, or a personal account of a legal representative in case of younger passengers. A passenger would utilise their mobile phone as a payment as well as a loyalty card. The communication between a mobile phone and a reader would be in a "Read/Write" mode [11, 25]. In this scenario it would be necessary for the passenger to register themselves at the carrier which could be done in the same way as in case of registering a contactless chip card. This system would be more comfortable for the passenger since the only duty would be the verification at check-in and checkout of the system, and everything else would be operated by a sophisticated payment and identification system.

The first step to use a mobile phone with an active NFC chip would be a required activation of the NFC chip into the complex system of regional passenger transport. A process which would provide the activation of the NFC chip, and thus the determination of a Secure Element for a passenger 


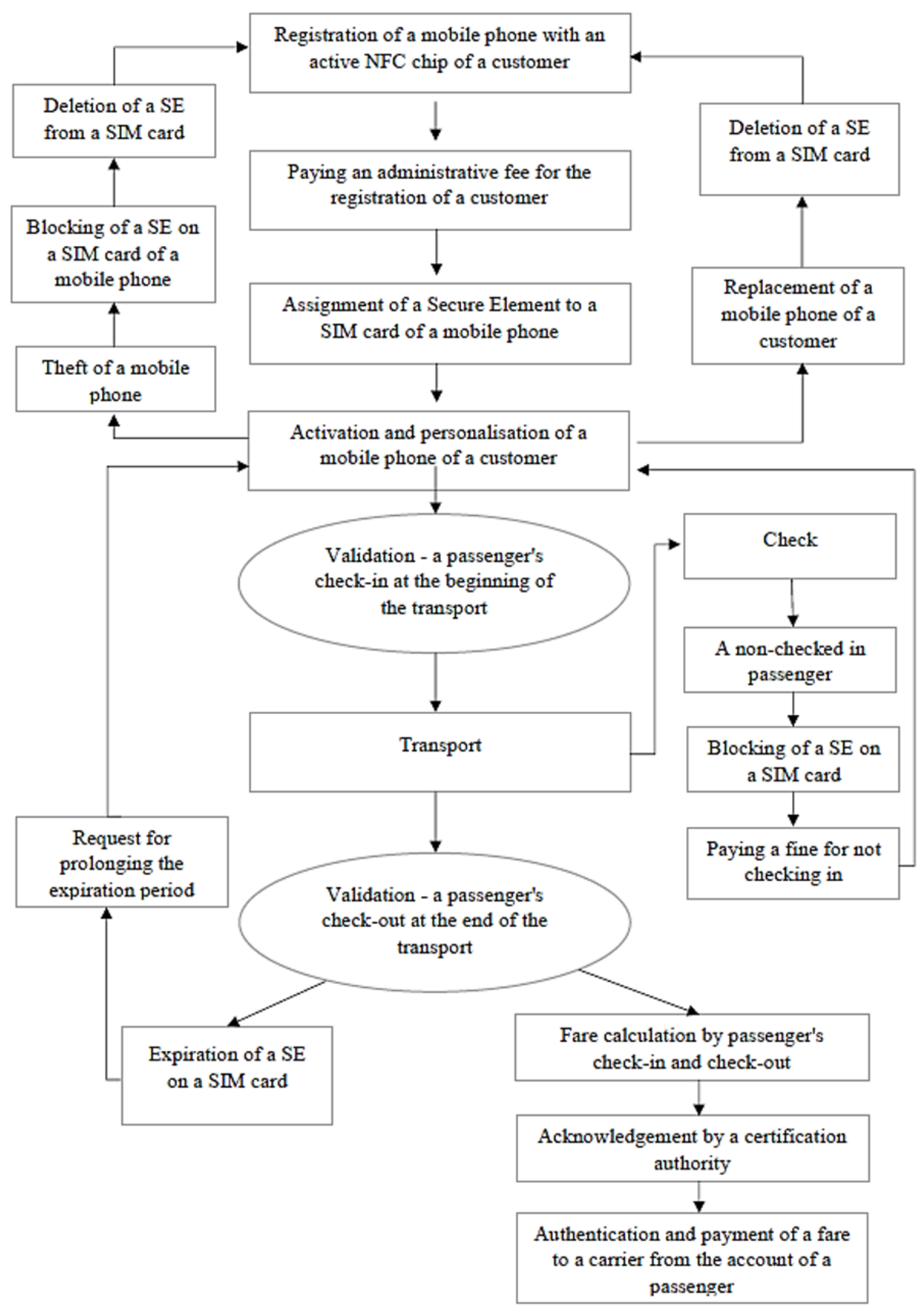

Figure 3: A Model Diagram of Using NFC Technology in a Mobile Phone with an Active NFC Chip (Source: the Authors). 
would represent the starting point of the entire activation process. There exist three forms of placing the Secure Element: Secure Element in a SIM card, an external Secure Element in the form of a memory card, and a Host Card Emulation [26]. For this proposal the placement Secure Element in a SIM card has been chosen. Subsequently a passenger would pay for the activation of the NFC chip in a mobile phone (the analogy would lie in buying a contactless chip card - a regional passenger transport card). After paying the fee the activated Secure Element would be saved onto the SIM card of the passenger, based on which the passenger would always be identified at the check-in or check-out of the system. This would be the last step of personalisation and activation of the NFC chip, and the mobile phone would become a registered active element in the system of passenger handling within regional passenger transport. The activation could be done with a given expiration period or without restricting it. After the expiration date the Secure Element on the SIM card of a mobile phone could be reactivated or removed from the system of regional passenger transport.

A mobile phone with an active NFC chip could be activated for just a few days, too, in case of using this service by tourists. During a ticket check an inspector could filter out a list of Secure Elements, or SIM cards from the group of checked in passengers, so they may check if the passengers are checked in the system, and thus do pay for the transport. There could be an obstacle - a replacement of a mobile phone by a passenger, or a change of a mobile services operator, when a new SIM card is issued. In such a case the Secure Element should be cleared from the system and a new activation and personalisation of a customer would be needed.

Neither this proposal requires a link to personal accounts of passengers (or their legal representatives); however, there exists an option to deposit cash onto a personalised mobile phone. In that case the passenger would have to check the account (card) balance which could be removed thanks to EMV technology. Also in this case there would be applied a system of electronic tickets, a so called e-ticketing.

Figure 3 depicts a diagram of a model ticket in a mobile phone with and active NFC chip.

\section{Conclusion}

The development of information technologies and their overall global utilisation contributes to a better quality of transport services. Pro-customer oriented transport ser- vices with a greater comfort for passengers, not only with regard to a payment for provided services, reflect an upcoming trend in the development of a global society. This article presents two proposals for the introduction of NFC technology into the system of passenger handling. The proposals apply a Check-In/Check-Out validation when the validators are placed into vehicles. The first proposal lies in the implementation of NFC technology in regional passenger transport using an electronic wallet. This proposal assumes a Card Emulation communication mode between a medium (a contactless chip card) and NFC reader (NFC reader is passive and it reads the data from an active NFC chip placed into a contactless chip card). The second proposal represents the implementation of NFC technology in regional passenger transport using mobile phones with an active NFC chip. This proposal assumes a Read/Write communication mode between a medium (a mobile phone with an active NFC chip) and NFC reader. The first step to use a mobile phone with an active NFC chip would be an activation of the NFC chip and its related determination of a Secure Element. The Secure Element is important from the point of view of identification of the passenger when checking in/out of the system of passenger handling. There is a disadvantage of this proposal - a problem with identification of a passenger during a check, since there is a photograph on a card, but not on a mobile phone. Due to this it would be necessary to assign a passenger's photograph within the list of Secure Elements. The article also describes peculiarities and obstacles of using a mobile phone with an active NFC chip.

Acknowledgement: The paper was supported by the VEGA Agency, Grant No. 1/0019/17 "Evaluation of regional rail transport in the context of regional economic potential with a view to effective use of public resources and social costs of transport", at Faculty of Operations and Economics of Transport and Communication, University of Žilina, Slovakia.

\section{References}

[1] Gasparik J, Stopka O, Peceny L. (2015). Quality evaluation in regional passenger rail transport. Nase More, Dubrovnik: University of Dubrovnik, Vol. 62 (3), pp. 114-118. ISSN 0469-6255. DOI: https://doi.org/10.17818/NM/2015/SI5.

[2] L'upták V, Droździel P, Stopka O, Stopková M, Rybicka I. Approach methodology for comprehensive assessing the public passenger transport timetable performances at a regional scale. Sustainability. 2019;11(13):3532.

[3] Rymarz J, Niewczas A, Stokłosa J. (2015), Reliability Evaluation Of The City Transport Buses Under Actual Conditions. Transport 
\& Telecommunication, Vol. 16 (4). Pp. 259-266, ISSN 1407-6160. https://doi.org/10.1515/ttj-2015-0023.

[4] Near Field Communication. Technology standards. Available online: http://nearfieldcommunication.org/technology.html.

[5] Stopka O, Ponický J, Chovancová M, Zitrický V. Draft method for determining the number of checking devices utilized within the regional passenger transport. Nase More (Dubr). 2016;63(3):200-3.

[6] Halás M, Zitrický V, Blaho P. (2013) Searching for the weaknesses of existing regional railway lines. Logi - Scientific Journal on Transport and Logistics, Vol. 4 (1), pp. 53 - 62, ISSN 1804-3216.

[7] Dolinayova A, Masek J, Kendra M, Camaj J, et al. Research of the Passenger's Preferences and Requirements for the Travel Companion Application. Journal of Advanced Transportation. Article. 2018;(8092147): https://doi.org/10.1155/2018/8092147.

[8] Wińska, M., Gzik, A. (2019). Determining the level of satisfaction among users of public transport in Lublin. The Archives of Automotive Engineering - Archiwum Motoryzacji, 85(3), 19-39. DOI: https://doi.org/10.14669/AM.VOL85.ART2.

[9] Intelligent transport system. White paper of the application of public transport. (2013). Available online: http://www.fome nto.gob.es/NR/rdonlyres/F5BBB37E-F29E-4C47-AE7B-77C387 5CAC92/122698/White_Paper_NFC.pdf

[10] Cerna L, Zitricky V, Danis J. The Methodology of Selecting the Transport Mode form Companies on the Slovak Transport Market. Open Eng. 2017;7(1):6-13.

[11] NFC in Public Transport. (2013) Available online: http://nfcforum.org/wp-content/uploads/2013/12/NFC-in-Public-Trans port.pdf.

[12] Puhe M, et al. (2014) Integrated urban e-ticketing for public transport and touristic sites. Available online: http://urban-intergro up.eu/wp-content/files_mf/ipoljoin_et2014513551_en.pdf.

[13] https://www.ov-chipkaart.nl.

[14] Tengler J, Kolarovski P, Kolarovszka Z, Perakovi D. (2017), Development of Smart Tool for Efective logistics Processes Measurement, In: Carpathian Logistics Congress. (Zakopane, Poland), Nov. 28-30. Zakopane, 198-203.

[15] Lizbetin J, Bartuska L. (2017), The Influence of Human Factor on Congestion Formation on Urban Roads, In: Transbaltica 2017: Transportation science and technology. Paper presented at $10^{\text {th }}$ International Scientific Conference on transportation Science and Technology, (Vilnius, Lithuania), May 04-05, Vilnius, 206-211. https://doi.org/10.1016/j.proeng.2017.04.366.
[16] Stopka O, Bartuska L, Kampf R. (2015) Passengers' evaluation of the integrated transport systems. Nase More, Dubrovnik: University of Dubrovnik, 2015, Vol. 62 (3), pp. 153-157. ISSN 0469-6255. DOI: https://doi.org/10.17818/NM/2015/SI12.

[17] Rybicka I, Drozdziel P, Stopka O, Luptak V. Methodology to Propose a Regional Transport Organization within Specific Integrated Transport System: a Case Study. Transp Probl. 2018;13(4):115-25.

[18] Abramović B. Passenger's satisfaction on long distance terminals: Case study city of Zagreb. Volume 45. Periodica Polytechnica Transportation Engineering; 2017. p. 1.

[19] Ewhrudjakpor, O., Poliaková, A., Poliak, M. (2019). The Integration of Passenger Transport and Integration Barriers. The Archives of Automotive Engineering - Archiwum Motoryzacji, 85(3), 103-113. DOI: https://doi.org/10.14669/AM.VOL85.ART7.

[20] Fedorko G, Rosová A, Molnár V. The application of computer simulation in solving traffic problems in the urban traffic management in Slovakia. Theor. Empir. Res. Urban Manag. 2014;9:5-17.

[21] Komsta H, Brumercikova E, Bukova B. Application of NFC technology in passenger rail transport. Transp Probl. 2016;11(3):43-53.

[22] Konečný, V., Berežný, R., Petro, F., Trnovcová, M. (2017). Research on Demand for Bus Transport and Transport Habits of High School Students in Žilina Region. LOGI - Scientific Journal on Transport and Logistics, 8(2), pp. 47-58. DOI: https://doi.org/10.1515/logi2017-0016.

[23] The system uses EMV cards in passenger transport. Available online: http://www.prerov.eu/filemanager/files/file.php ?file $=41299$.

[24] Chovancova M, Klapita V. Modeling the Supply Process Using the Application of Selected Methods of Operational Analysis. Open Engineering, Vol. 2017;7(1):50-4.

[25] A few words about Y-generations (millenians). (in Slovak). Available online: https://alkp.sk/co-na-vas-plati-ak-ste-z-generaciexy-z-alebo-alfa-a-viete-ake-generacie-boli-pred-vami/.

[26] Gnap J., Rovňaníková D., Jaśkiewicz M. (2017). Temperature Control for Regional Transport. LOGI - Scientific Journal on Transport and Logistics, 8(2), pp. 81-89. https://doi.org/10.1515/logi-20170019. 